\title{
Análise Multivariada das Medidas Morfométricas de Potros da Raça Mangalarga Marchador: Análise Fatorial ${ }^{1}$
}

\section{Luís Fernando Batista Pinto², Fernando Queiroz de Almeida3, Pedro Cezar Nehme de Azevedo ${ }^{4}$, Célia Raquel Quirino ${ }^{5}$, Grasiele Coelho Cabral ${ }^{2}$, Edson Mauro Santos ${ }^{2}$}

\begin{abstract}
RESUMO - Objetivou-se, neste estudo, realizar avaliação morfológica de potros e potras da raça Mangalarga Marchador, adotandose a análise fatorial, durante o período de agosto de 2000 a junho de 2003 . Foram efetuadas 19 mensurações lineares, envolvendo altura, comprimento, largura e perímetros e 11 medidas angulares: na semana do nascimento, em 55 potros e 41 potras; aos seis meses de idade, em 35 potros e 37 potras; e aos doze meses de idade, em 19 potros e 31 potras. A análise fatorial foi empregada para verificar a existência de relações importantes entre as medidas morfométricas. Nas medidas lineares, geralmente foram observados de seis a sete fatores e as comunalidades obtidas com este número de fatores foram elevadas, ao passo que, nas medidas angulares, o número de fatores foi geralmente seis. Foram observadas correlações importantes entre as medidas lineares, as quais possibilitaram a identificação de fatores denominados sustentação, altura, rendimento, equilíbrio, carga, cefálico, robustez e perímetro, entre outros, enquanto, nas medidas angulares, foram identificados fatores que podem estar associados à comodidade, agilidade, rendimento, impulsão e força para o andamento.
\end{abstract}

Palavras-chave: eqüinos, medidas angulares, medidas lineares, morfologia

\section{Multivariate Analysis of Body Measures in Mangalarga Marchador Foals: Factorial Analysis}

\begin{abstract}
This work aims to evaluate the morphology of Mangalarga Marchador foals with Factorial Analysis from August, 2000 to June, 2003. Nineteen linear measures relating to height, length, width and girth and 11 angular measures were made at birth's week, in 55 colts and 41 fillies; at six months of age, in 35 colts and 37 fillies; and at twelve months of age, in 19 colts and 31 fillies. The factorial analysis was used to verify the existence of important relationships among morphometric measures. For linear measures, generally were observed six and seven factors and the communality obtained with this numbers of factors were high. However, for angular measures the number of factors was generally six. It was observed very important relationships among linear measures and it was possible to identify the factors as sustentation, height, efficiency, equilibrium, cargo, cephalic, robustness and girth among others, while for angular measures it was possible to identify factors associated with comfortableness, agility, efficiency, impulsion and force for gait.
\end{abstract}

Key Words: angular measures, horse, linear measures, morphology

\section{Introdução}

A raça Mangalarga Marchador é a raça nacional mais numericamente expressiva, com cerca de 300.000 animais e com padrão racial definido pela Associação Brasileira dos Criadores de Cavalo Mangalarga Marchador (ABCCMM, 2003), que se baseia na aparência externa e na mensuração da altura na cernelha dos animais, nos quais a presença do andamento marchado é obrigatória. Este andamento característico nos eqüinos da raça Mangalarga
Marchador resulta da coordenação neuromotora dos movimentos, do treinamento e de medidas morfométricas adequadas. Desse modo, é necessário avaliar medidas lineares de altura, comprimento, distância, perímetro e largura, além das medidas angulares dos raios ósseos das principais articulações envolvidas com a dinâmica do andamento.

A análise fatorial tem como principal propósito avaliar as relações entre as variáveis observadas em função dos fatores, os quais são variáveis aleatórias latentes não-observáveis. As variáveis são agrupadas

\footnotetext{
1 Parte da Dissertação do primeiro autor apresentada ao Programa de Pós-graduação em Zootecnia da UFRRJ. Projeto de pesquisa financiado pela FAPERJ.

2 Zootecnista. Mestre em Zootecnia - UFRRJ - Seropédica - RJ.

3 Professor Adjunto. Instituto de Veterinária - UFRRJ. Bolsista do CNPq

Correspondência: DMCV-IV-UFRRJ. BR 465, km 7, Seropédica, RJ. CEP:23890-000.E.mail: falmeida@ufrrj.br

${ }^{4}$ Professor Adjunto. Departamento de Genética - IB - UFRRJ. Seropédica, RJ. CEP:23890-000. E.mail: nehme@ufrrj.br

5 Professor Associado - LMGA-CCTA-UENF - Campos dos Goytacazes - RJ. E.mail: crq@uenf.br
} 
de forma que dentro de cada fator apresentem alta correlação com algumas medidas, mas relativamente menores correlações com variáveis agrupadas em outros fatores. Os fatores possuem coeficientes que os associam às diferentes variáveis originais, os pesos fatoriais, medindo, desta forma, a correlação da variável original com o fator considerado (Ribeiro Jr., 2001).

Estudos morfológicos em eqüinos empregandose a análise fatorial e envolvendo medidas lineares e angulares são escassos na literatura. Barbosa (1993) utilizou esta metodologia para avaliar as medidas lineares de animais adultos da raça Mangalarga Marchador e observou a formação de sete fatores, que receberam nomes apropriados em função do grau de associação com as variáveis em estudo. Nos machos não-campeões, os fatores foram denominados F1 - fator paralelogramo, F2 - fator dinâmica, F3 - fator robustez, F4 - fator carga, F5 - fator balanço, F6 - fator sustentação e F7 - fator cranial. Nos machos campeões, F1 não foi identificado por estar associado a várias medidas corporais, F2 - fator paralelogramo, F3 - fator equilíbrio, F4 - fator carga, F5 - fator robustez, F6 - fator cranial e F7 - fator cefálico. Nas fêmeas não-campeãs, os fatores foram os mesmos para os machos nãocampeões, embora não na mesma ordem, enquanto, nas fêmeas-campeãs, foi identificado um novo fator denominado feminilidade, por estar associado aos valores de largura da anca, comprimento da garupa e comprimento do corpo.

Mais recentemente, Lage (2001), utilizando a análise de correlação avaliou medidas lineares, angulares, de aprumos e os atributos de marcha de animais adultos da raça Mangalarga Marchador. O comprimento da escápula apresentou associação de 0,16 com o rendimento do andamento marchado. As associações entre os atributos de marcha e as medidas morfológicas variaram de baixo a moderado de 0,16 a 0,26 . A qualidade dos aprumos apresentou associação com os atributos de marcha, com valores de 0,17 a 0,54 .

Portanto, mensurações podem e devem ser obtidas nos potros, uma vez que a comercialização destes animais é responsável por grande parte da receita bruta dos criatórios. Além disso, conhecendo o padrão de desenvolvimento corporal dos animais e as relações entre as medidas, é possível propor e fornecer ferramentas que possibilitem selecionar, com acurácia elevada, os animais ainda em idade precoce como no desmame, evitando o descarte equivocado de animais no ato da comercialização.

O objetivo, neste trabalho, foi avaliar as relações existentes entre as medidas lineares e angulares de potros e potras da raça Mangalarga Marchador ao nascimento, aos seis e aos doze meses de idade, utilizando-se a metodologia de análise fatorial.

\section{Material e Métodos}

O trabalho foi desenvolvido na Universidade Federal Rural do Rio de Janeiro, utilizando dados de animais oriundos de diversos criatórios de regiões circunvizinhas ao campus universitário, de agosto de 2000 a junho de 2003. As medidas foram feitas na semana do nascimento dos potros, em um grupo de 55 potros e 41 potras; aos seis meses de idade, em um grupo de 35 potros e 37 potras; e aos doze meses de idade, em um grupo de 19 potros e 31 potras.

As mensurações foram feitas com os animais em estação forçada, isto é, membros, anterior e posterior, na perpendicular sobre um piso plano, formando um paralelogramo retangular, de forma que, vistos de perfil, seus membros, para cada bípede, se encobrem, e vistos de frente ou detrás, estão na vertical e igualmente apoiados no piso. As medidas foram obtidas sempre do lado direito do animal, utilizando-se hipômetro, fita métrica, artrogoniômetro e angulador de casco.

Foram efetuadas as seguintes medidas lineares: altura na cernelha, na garupa e no costado; comprimentos do corpo, da garupa, do dorso-lombo, da escápula, do pescoço e da cabeça; larguras do peito e da anca; distâncias do codilho ao solo, da soldra ao jarrete e do jarrete ao boleto; perímetros torácico, do antebraço, do joelho, do boleto e da canela. Além destas, foram efetuadas as seguintes medidas angulares: escápulo-solo, escápulo-umeral, úmero-radial, metacarpo-falangeano, falangeano-solo-anterior, coxal-solo, coxofemoral, fêmur-tibial, tíbiometatarsiano, metatarso-falangeano e falangeanosolo-posterior.

Todas as mensurações foram efetuadas segundo Camargo \& Chieffi (1971), Brito (1990), Barbosa (1993), Thompson (1995), Cabral (2002) e Cabral et al.(2004ab)

O procedimento de rotação varimax foi o modelo adotado para a rotação dos fatores, que é recomendado sempre que existe dificuldade em interpretar os fatores. A rotação consiste em transformar os fato-

\section{R. Bras. Zootec., v.34, n.2, p.613-626, 2005}


res iniciais de forma que fiquem oblíquos ou ortogonais, simplificando a estrutura dos fatores. Neste trabalho, utilizou-se a rotação ortogonal, procedimento varimax, pois, segundo Khattree \& Naik (2000), este modelo torna os fatores independentes. O número de fatores extraídos foi estabelecido em função do critério da variância, que estabelece um percentual mínimo de $80 \%$ da variância explicada como determinante do número de fatores a ser considerado. O significado dos fatores foi estabelecido de acordo com os pesos fatoriais das variáveis em cada fator. Foram considerados como significativos intermediários os pesos fatoriais maiores que $\pm 0,30 \mathrm{e}$, como muito significativos, os pesos maiores que $\pm 0,50$. Os dados obtidos foram submetidos a análise fatorial segundo Khattree \& Naik (2000), por intermédio do programa STATISTICA for Windows 5.0 (1995).

\section{Resultados e Discussão}

Nas Tabelas 1 e 2, podem ser observados os pesos fatoriais e as comunalidades de cada variável em relação aos respectivos fatores, em potros e potras recém-nascidos, respectivamente. Pode ser observado que os valores das comunalidades foram geralmente altos. Segundo Morrison (1976), as comunalidades representam o quanto da variação da característica é explicado pelo número de fatores que está sendo considerado.

Nos potros recém-nascidos, o primeiro fator apresentou as alturas na cernelha, na garupa e no costado, os perímetros do tórax, do antebraço, do joelho, do boleto e da canela e a largura da anca com os maiores pesos fatoriais. Todos os pesos fatoriais apresentaram sinal positivo, logo estavam diretamente correlacionados.

Tabela 1- Pesos fatoriais e comunalidades (C) das medidas lineares de potros recém-nascidos

Table 1 - Factorial weight and comunalities (C) from linear measures in newly born colts

\begin{tabular}{|c|c|c|c|c|c|c|c|c|c|}
\hline \multirow[b]{2}{*}{$\begin{array}{l}\text { Variável } \\
\text { Measure }\end{array}$} & \multirow[b]{2}{*}{$\mathrm{C}$} & \multicolumn{6}{|c|}{$\begin{array}{l}\text { Fator } \\
\text { Factor }\end{array}$} & \multirow[b]{2}{*}{$\begin{array}{c}\mathrm{F} 7 \\
\text { Rendimento } \\
\text { Efficiency }\end{array}$} & \multirow[b]{2}{*}{$\begin{array}{c}\mathrm{F} 8 \\
\text { Equilíbrio } \\
\text { Equilibrium }\end{array}$} \\
\hline & & $\begin{array}{c}\text { F1 } \\
\text { Sustentação } \\
\text { Sustentation }\end{array}$ & $\begin{array}{l}\text { F2 } \\
\text { Robustez } \\
\text { Robustness }\end{array}$ & $\begin{array}{c}\text { F3 } \\
\text { Carga } \\
\text { Weight }\end{array}$ & $\begin{array}{c}\text { F4 } \\
\text { Cefálico } \\
\text { Cephalic }\end{array}$ & $\begin{array}{c}\mathrm{F} 5 \\
?\end{array}$ & $\begin{array}{c}\text { F6 } \\
\text { Sincronismo } \\
\text { Synchronism }\end{array}$ & & \\
\hline $\mathrm{AC}$ & 0,82672 & 0,83784 & 0,06276 & 0,14222 & 0,03283 & 0,12931 & $-0,20991$ & 0,13507 & 0,14309 \\
\hline $\mathrm{AG}$ & 0,84777 & 0,87141 & $-0,05607$ & 0,06787 & 0,06800 & 0,14806 & $-0,12196$ & 0,17327 & 0,09600 \\
\hline ACOS & 0,77184 & 0,75964 & 0,33153 & 0,14341 & 0,19272 & 0,03913 & 0,07494 & 0,04842 & 0,13291 \\
\hline $\mathrm{CC}$ & 0,75161 & 0,34489 & 0,64246 & $-0,02215$ & 0,34079 & 0,07016 & 0,03541 & 0,11953 & 0,28778 \\
\hline CG & 0,79998 & 0,39645 & 0,78648 & 0,01709 & 0,03444 & $-0,09233$ & $-0,03557$ & $-0,01698$ & 0,11268 \\
\hline CDL & 0,91172 & 0,08784 & 0,06203 & 0,91607 & 0,13884 & $-0,13456$ & $-0,00074$ & 0,11624 & 0,10034 \\
\hline $\mathrm{CE}$ & 0,86763 & 0,24809 & 0,22021 & 0,19447 & 0,19713 & 0,11196 & $-0,02713$ & 0,81250 & $-0,08650$ \\
\hline $\mathrm{CP}$ & 0,85715 & 0,19680 & 0,19175 & 0,08242 & 0,11093 & 0,09088 & 0,04972 & $-0,02652$ & 0,86667 \\
\hline CCAB & 0,91758 & 0,17431 & 0,17775 & 0,17252 & 0,88724 & 0,10626 & $-0,01677$ & 0,14877 & 0,07030 \\
\hline LA & 0,82920 & 0,53619 & 0,22846 & $-0,05560$ & $-0,08240$ & $-0,31669$ & 0,00820 & 0,53386 & 0,30701 \\
\hline LP & 0,79884 & $-0,00760$ & 0,83277 & 0,13843 & 0,06396 & $-0,10189$ & 0,05128 & 0,26229 & $-0,01456$ \\
\hline DCS & 0,81120 & 0,21089 & $-0,08077$ & $-0,22444$ & 0,18096 & 0,81497 & 0,04519 & 0,01128 & 0,10360 \\
\hline DSJ & 0,82251 & 0,26974 & $-0,10842$ & 0,17513 & $-0,34545$ & 0,51004 & $-0,30665$ & 0,07387 & 0,47787 \\
\hline DjaB & 0,93669 & 0,24633 & 0,00471 & 0,00149 & 0,00176 & 0,00266 & $-0,93534$ & 0,02280 & $-0,02436$ \\
\hline PT & 0,76369 & 0,42141 & 0,50892 & $-0,21456$ & 0,09229 & 0,24869 & $-0,26426$ & 0,31361 & 0,20620 \\
\hline PA & 0,71688 & 0,60284 & 0,41745 & $-0,24210$ & $-0,03822$ & 0,08338 & $-0,28145$ & $-0,18078$ & $-0,01676$ \\
\hline PJ & 0,77478 & 0,71897 & 0,28550 & $-0,09036$ & 0,15214 & 0,18661 & $-0,08037$ & 0,27658 & 0,16510 \\
\hline PB & 0,75512 & 0,70146 & 0,38443 & $-0,07484$ & 0,13994 & 0,03998 & $-0,21000$ & 0,09363 & 0,18877 \\
\hline $\mathrm{PC}$ & 0,80775 & 0,61496 & 0,31169 & 0,13588 & $-0,26247$ & 0,41255 & $-0,12854$ & 0,21332 & $-0,11332$ \\
\hline \multicolumn{2}{|c|}{$\begin{array}{l}\text { Explicação } \\
\text { Explication }\end{array}$} & 0,39594 & 0,11177 & 0,07291 & 0,06492 & 0,05433 & 0,04494 & 0,04110 & 0,03349 \\
\hline
\end{tabular}

AC - altura na cernelha; AG - altura na garupa; Acos - altura do costado; CC - comprimento do corpo; CG - comprimento da garupa; $\mathrm{CDL}$ - comprimento do dorso-lombo; CE - comprimento da escápula; CP - comprimento do pescoço; Ccab - comprimento da cabeça; LA - largura da anca; LP - largura do peito; DCS - distância do codilho ao solo; DSJ - distância da soldra ao jarrete; DjaB - distância do jarrete ao boleto; PT - perímetro torácico; PA - perímetro do antebraço; PJ - perímetro do joelho; PB - perímetro do boleto; PC - perímetro da canela.

AC - Withers height; AG - Croup height; ACos - chest depth; CC - body length; CG - croup length; CDL - back-loins length; CE - shoulder length; CP - neck length; Ccab - head length; LA - hips width; LP - chest width; DCS - distance between elbow and floor; DSJ - distance between stifle and hock; DJaB - distance between hock and fetlock; PT - chest girth; PA - forearm girth; PJ - knee girth; PB - fetlock girth; PC - cannon girth.

R. Bras. Zootec., v.34, n.2, p.613-626, 2005 
Tabela 2 - Pesos fatoriais e comunalidades (C) das medidas lineares de potras recém-nascidas Table 2 - Factorial weight and comunalities (C) from linear measures in newly born fillies

\begin{tabular}{|c|c|c|c|c|c|c|c|}
\hline \multirow{4}{*}{$\begin{array}{l}\text { Variável } \\
\text { Measure }\end{array}$} & \multirow{4}{*}{$\mathrm{C}$} & \multicolumn{5}{|c|}{$\begin{array}{l}\text { Fator } \\
\text { Factor }\end{array}$} & \multirow{4}{*}{$\begin{array}{c}\text { F6 } \\
?\end{array}$} \\
\hline & & $\mathrm{F} 1$ & $\mathrm{~F} 2$ & $\mathrm{~F} 3$ & F4 & F5 & \\
\hline & & Sustentação & Altura & $?$ & Perímetro & Equilíbrio & \\
\hline & & Sustentation & Height & & Girth & Equilibrium & \\
\hline $\mathrm{AC}$ & 0,9121 & 0,52464 & 0,66123 & 0,37469 & 0,09051 & 0,00683 & 0,22594 \\
\hline $\mathrm{AG}$ & 0,8780 & 0,50077 & 0,65247 & 0,34465 & 0,03783 & 0,03929 & 0,28251 \\
\hline ACOS & 0,8361 & 0,68480 & 0,21581 & 0,48354 & $-0,10491$ & 0,04149 & 0,27214 \\
\hline $\mathrm{CC}$ & 0,8280 & 0,73087 & 0,25736 & 0,38368 & 0,15812 & 0,20270 & 0,11963 \\
\hline CG & 0,8176 & 0,77889 & $-0,03370$ & 0,24307 & 0,25776 & 0,18154 & 0,22660 \\
\hline CDL & 0,7690 & 0,05805 & $-0,13667$ & 0,77982 & 0,28949 & 0,23335 & 0,02511 \\
\hline $\mathrm{CE}$ & 0,8196 & 0,35111 & 0,23976 & 0,74721 & 0,06055 & 0,27177 & 0,05515 \\
\hline $\mathrm{CP}$ & 0,8256 & 0,35720 & 0,15546 & 0,32096 & $-0,00570$ & 0,69432 & 0,29797 \\
\hline $\mathrm{CCAB}$ & 0,7472 & 0,24893 & 0,30432 & 0,74957 & 0,15451 & 0,08272 & 0,01036 \\
\hline LA & 0,7510 & 0,66061 & 0,24115 & 0,43220 & 0,25057 & 0,03692 & 0,07440 \\
\hline $\mathrm{LP}$ & 0,9144 & 0,47366 & $-0,07703$ & 0,72173 & 0,02910 & $-0,36384$ & 0,17343 \\
\hline DCS & 0,8092 & 0,25918 & 0,69005 & 0,17424 & $-0,03658$ & 0,38396 & 0,29572 \\
\hline DSJ & 0,9025 & 0,08054 & 0,34616 & 0,03764 & 0,12454 & 0,17817 & 0,85299 \\
\hline DjaB & 0,8458 & $-0,00008$ & 0,86565 & $-0,10076$ & 0,28440 & $-0,00512$ & 0,07377 \\
\hline PT & 0,8897 & 0,78784 & 0,17271 & 0,44132 & 0,14941 & $-0,02276$ & 0,14699 \\
\hline PA & 0,8214 & 0,86137 & 0,15350 & $-0,03929$ & 0,13671 & 0,16994 & $-0,08271$ \\
\hline PJ & 0,8398 & 0,69167 & 0,24545 & 0,18952 & 0,50847 & 0,06153 & $-0,05388$ \\
\hline PB & 0,8638 & 0,34630 & 0,25350 & 0,24597 & 0,74581 & $-0,04424$ & 0,24693 \\
\hline $\mathrm{PC}$ & 0,7459 & 0,50386 & 0,15320 & 0,42953 & 0,52535 & 0,04016 & $-0,08036$ \\
\hline \multicolumn{2}{|c|}{$\begin{array}{l}\text { Explicação } \\
\text { Explication }\end{array}$} & 0,53197 & 0,10724 & 0,06884 & 0,05276 & 0,03854 & 0,03320 \\
\hline
\end{tabular}

AC - altura na cernelha; AG - altura na garupa; Acos - altura do costado; CC - comprimento do corpo; CG - comprimento da garupa; CDL - comprimento do dorso-lombo; CE - comprimento da escápula; CP - comprimento do pescoço; Ccab - comprimento da cabeça; LA - largura da anca; LP - largura do peito; DCS - distância do codilho ao solo; DSJ - distância da soldra ao jarrete; DjaB - distância do jarrete ao boleto; PT - Perímetro torácico; PA - perímetro do antebraço; PJ - perímetro do joelho; PB - perímetro do boleto; PC - perímetro da canela.

$A C$ - withers height; $A G$ - croup height; $A C$ Cos - chest depth; $C C$ - body length; $C G$ - croup length; $C D L$ - back-loins length; $C E$ - shoulder length; $C P$ - neck length; Ccab - head length; LA - hips width; LP - chest width; DCS - distance between elbow and floor; DSJ - distance between stifle and hock; DJaB - distance between hock and fetlock; PT - chest girth; PA - forearm girth; PJ - knee girth; PB - fetlock girth; PC - cannon girth.

Por este motivo, o fator foi denominado sustentação, pois relacionou as medidas de altura com os perímetros. As medidas de altura e o perímetro torácico, nos eqüinos, estão altamente relacionadas ao peso dos animais. Ficou bastante evidente que potros recém-nascidos maiores precisam de maiores perímetros nos membros anteriores para que haja perfeita sustentação da massa corpórea.

O segundo fator foi denominado robustez e foi observado por Barbosa (1993) em animais adultos, porém, aqui os valores foram semelhantes apenas quanto ao perímetro torácico. Com base neste fator, os potros recém-nascidos devem apresentar-se com o tronco equilibrado, ou seja, com medidas proporcionais, principalmente no que diz respeito à largura do peito, aos comprimentos da garupa e do corpo e ao perímetro torácico.

O terceiro e o quarto fatores, nos potros, tiveram as medidas de comprimento do dorso-lombo e da cabeça, respectivamente, com os maiores pesos fatoriais, permitindo concluir que estas medidas foram pouco correlacionadas às demais medidas nesta idade. O F3 foi denominado carga, pois a região do dorso-lombo é o ponto de apoio da carga que o animal deve transportar, enquanto o F4 foi denominado cefálico por apresentar apenas a medida de comprimento da cabeça com elevado peso fatorial.

$\mathrm{O}$ quinto fator nos potros apresentou as medidas das distâncias do codilho ao solo e da soldra ao jarrete com os maiores pesos fatoriais. Este agrupamento não foi satisfatório para identificação do fator, sendo observado também em sexto lugar nas potras desta faixa etária e também não classificado.

O sexto fator dos potros foi denominado sincronismo, pois apresentou peso fatorial elevado apenas para a medida de distância do jarrete ao boleto. Andrade (1986) afirma que a altura do jarrete deve estar situada em um ponto médio, ou seja, nem 
alto nem baixo, que é determinado pelos comprimentos da tíbia e da canela; uma tíbia curta e uma canela longa levam o animal a tocar com a pinça dos cascos posteriores a parte posterior dos membros anteriores, causando lesões. O contrário, tíbia longa e canela curta, indica que os membros posteriores do animal poderão apresentar dificuldades em acompanhar os movimentos dos anteriores, comprometendo a velocidade e o rendimento do andamento marchado. Essas considerações induziram a denominação sincronismo, pois a medida da distância entre a soldra e o jarrete apresentou peso fatorial significativo apesar de ser inferior ao peso fatorial da distância do jarrete ao boleto. Ambas apresentaram peso fatorial positivo, logo variações em uma destas medidas são acompanhadas de variações proporcionais na outra medida.

O fator F7 nos potros foi classificado como Rendimento, pois relacionou as medidas de comprimento da escápula e de largura da anca, ambas com pesos fatoriais positivos. A região do posterior dos eqüinos tem como principal função gerar a força necessária para o deslocamento, enquanto a escápula atua transformando a força gerada pelo posterior em capacidade de deslocamento. Logo, à medida que aumenta o volume da região posterior, ocorre avanço proporcional da escápula para responder a maior força gerada pelo posterior, promovendo ganhos em rendimento do andamento.

$\mathrm{O}$ fator F8 nos potros e o quinto nas potras foram classificados como equilíbrio, por apresentarem como única variável altamente significativa o comprimento do pescoço, estrutura utilizada pelo animal durante $\mathrm{o}$ andamento para deslocar horizontalmente o centro de gravidade.

O primeiro fator das potras apresentou as medidas de altura na cernelha, na garupa e do costado, comprimento do corpo e da garupa, largura da anca e perímetros do tórax, do antebraço, do joelho e da canela com os maiores pesos fatoriais, todos positivos. Portanto, como nos potros, foi classificado como sustentação. O fator F2 foi classificado como Altura e envolveu as medidas de altura na cernelha, na garupa e a distância do codilho ao solo, que representa a altura do vazio subesternal e a distância jarreteboleto, observando-se pesos fatoriais positivos para estas medidas. O terceiro fator apresentou dificuldades de interpretação por apresentar muitas variáveis com pesos fatoriais intermediários. O quarto fator foi considerado um novo fator e incluiu a relação entre as medidas de perímetro do joelho, do boleto e da canela, sendo denominado Perímetro, indicando equilíbrio no desenvolvimento destas estruturas.

Nas Tabelas 3 e 4, podem ser observados os pesos fatoriais e as comunalidades de cada variável em relação aos respectivos fatores em potros e potras com seis meses de idade, respectivamente.

$\mathrm{O}$ fator F1 dos potros foi denominado altura. As medidas de altura na cernelha, na garupa, do costado e a distância do codilho ao solo foram as que tiveram os maiores pesos fatoriais, todos positivos, indicando que animais mais altos também apresentaram maior altura do codilho, ou seja, maior espaço subesternal. Essa característica não é interessante para animais marchadores, pois, segundo Andrade (1986), um tronco muito afastado do solo tende a prejudicar o equilíbrio do cavalo durante o andamento.

$\mathrm{O}$ fator $\mathrm{F} 2$ foi denominado carga e, de forma semelhante ao observado nos machos recém-nascidos, apresentou apenas a medida de comprimento do dorso-lombo com elevado peso fatorial. Os fatores F3 e F8 apresentaram as medidas de distância do jarrete ao boleto e da soldra ao jarrete, respectivamente, com os maiores pesos fatoriais. Estas duas medidas separadas não denotaram sentido claro, como descrito no fator Sincronismo entre os potros recém-nascidos.

O fator F4 apresentou apenas o perímetro do boleto com o peso fatorial altamente significativo, o qual também não apresentou significado. Pode ser constatado apenas que esta medida teve baixa correlação com as demais nos potros com seis meses de idade. $\mathrm{O}$ fator $\mathrm{F} 5$ apresentou elevados pesos fatoriais para as medidas de perímetro torácico, altura do costado e largura da garupa, que dão boa dimensão do desenvolvimento do tronco do animal e que justificam a denominação (robustez) deste fator. Entretanto, observou-se a medida de comprimento da cabeça com o maior peso fatorial do fator em questão e, assim como os demais considerados, com valor positivo. Logo, potros aos seis meses de idade com o tronco mais desenvolvido tenderam a apresentar maiores medidas do comprimento da cabeça.

$\mathrm{O}$ fator F7 teve como principais medidas o comprimento da garupa e o comprimento do pescoço e ambas apresentaram pesos fatoriais negativos, o que confere correlação positiva entre as duas. Este fator foi denominado balanço, pois apresentou duas medidas opostas, uma de anterior e outra de posterior, capazes de controlar o deslocamento do centro de gravidade do corpo. Barbosa (1993) denominou ba-

R. Bras. Zootec., v.34, n.2, p.613-626, 2005 
Tabela 3 - Pesos fatoriais e comunalidades (C) das medidas lineares de potros com seis meses de idade Table 3 - Factorial weight and comunalities (C) from linear measures in colts with six months age

\begin{tabular}{|c|c|c|c|c|c|c|c|c|c|}
\hline \multirow{4}{*}{$\begin{array}{l}\text { Variável } \\
\text { Measure }\end{array}$} & \multirow{4}{*}{$\mathrm{C}$} & \multicolumn{6}{|c|}{$\begin{array}{l}\text { Fator } \\
\text { Factor }\end{array}$} & \multirow[b]{2}{*}{$\mathrm{F} 7$} & \multirow[b]{2}{*}{ F8 } \\
\hline & & $\mathrm{F} 1$ & $\mathrm{~F} 2$ & F3 & F4 & F5 & F6 & & \\
\hline & & Altura & Carga & $?$ & $?$ & Robustez & Perímetro & Balanço & $?$ \\
\hline & & Height & Weight & & & Robustness & Synchronism & Balance & \\
\hline $\mathrm{AC}$ & 0,94550 & 0,88789 & $-0,01759$ & 0,00261 & 0,07716 & 0,20636 & $-0,22632$ & $-0,13120$ & $-0,19967$ \\
\hline $\mathrm{AG}$ & 0,91549 & 0,86479 & 0,13063 & 0,12349 & 0,05732 & 0,15190 & $-0,19770$ & $-0,24598$ & $-0,09671$ \\
\hline AÇOS & 0,85468 & 0,62463 & 0,03470 & $-0,03837$ & 0,26305 & 0,51618 & $-0,24650$ & $-0,10107$ & $-0,23499$ \\
\hline $\mathrm{CC}$ & 0,84689 & 0,54856 & 0,39531 & $-0,13016$ & 0,08198 & 0,49183 & 0,07521 & $-0,27308$ & 0,20956 \\
\hline CG & 0,80359 & 0,29368 & $-0,29042$ & 0,04487 & 0,30463 & 0,01311 & $-0,10295$ & $-0,72532$ & $-0,03632$ \\
\hline CDL & 0,88302 & 0,00168 & 0,90978 & $-0,11563$ & $-0,08457$ & $-0,08630$ & 0,03543 & 0,15732 & $-0,03672$ \\
\hline $\mathrm{CE}$ & 0,74043 & 0,49136 & 0,02613 & 0,12316 & $-0,42052$ & 0,32889 & $-0,23104$ & 0,22524 & $-0,30665$ \\
\hline $\mathrm{CP}$ & 0,84738 & 0,41191 & $-0,09587$ & $-0,25545$ & $-0,19149$ & 0,20714 & $-0,24495$ & $-0,62789$ & $-0,26353$ \\
\hline $\mathrm{CCAB}$ & 0,86036 & 0,25186 & $-0,22979$ & 0,11276 & 0,00101 & 0,84775 & $-0,04743$ & $-0,09149$ & 0,04592 \\
\hline LA & 0,81951 & 0,06793 & 0,23085 & 0,29435 & $-0,07312$ & 0,52079 & $-0,49888$ & $-0,26819$ & $-0,27854$ \\
\hline LP & 0,83060 & 0,21892 & 0,27437 & 0,21190 & 0,39957 & 0,40481 & $-0,28576$ & $-0,47352$ & $-0,18190$ \\
\hline DCS & 0,83164 & 0,72966 & $-0,31897$ & 0,22714 & 0,06167 & 0,20965 & $-0,25340$ & $-0,15933$ & $-0,09249$ \\
\hline DSJ & 0,88816 & 0,19283 & 0,01911 & 0,16812 & 0,08818 & 0,03976 & 0,00511 & $-0,13535$ & $-0,89143$ \\
\hline DjaB & 0,91509 & 0,19016 & $-0,14906$ & 0,90519 & $-0,06153$ & 0,06810 & 0,04343 & 0,04216 & $-0,15894$ \\
\hline PT & 0,84587 & 0,41461 & 0,05541 & $-0,10079$ & 0,30232 & 0,58646 & $-0,32938$ & 0,08092 & $-0,33223$ \\
\hline PA & 0,87564 & 0,45791 & $-0,22908$ & $-0,17274$ & 0,31119 & $-0,16188$ & $-0,67630$ & 0,01166 & 0,05549 \\
\hline PJ & 0,60602 & 0,60277 & 0,01198 & 0,30537 & 0,22649 & 0,12396 & $-0,07076$ & $-0,27266$ & $-0,05726$ \\
\hline PB & 0,79554 & 0,17461 & $-0,09529$ & $-0,03923$ & 0,84327 & 0,10279 & $-0,12609$ & $-0,09417$ & $-0,08944$ \\
\hline $\mathrm{PC}$ & 0,80777 & 0,25151 & $-0,00938$ & 0,00104 & 0,04712 & 0,24529 & $-0,80318$ & $-0,19197$ & $-0,00948$ \\
\hline $\begin{array}{l}\text { Explic } \\
\text { Explica }\end{array}$ & $\begin{array}{l}\text { ção } \\
\text { tion }\end{array}$ & 0,40485 & 0,09308 & 0,08247 & 0,06245 & 0,05525 & 0,05388 & 0,04764 & 0,03792 \\
\hline
\end{tabular}

AC - altura na cernelha; AG - altura na garupa; Acos - altura do costado; CC - comprimento do corpo; CG - comprimento da garupa; CDL - comprimento do dorso-lombo; CE - comprimento da escápula; CP - comprimento do pescoço; Ccab - comprimento da cabeça; LA - largura da anca; LP - largura do peito; DCS - distância do codilho ao solo; DSJ - distância da soldra ao jarrete; DjaB - distância do jarrete ao boleto; PT - perímetro torácico; PA - perímetro do antebraço; PJ - perímetro do joelho; PB - perímetro do boleto; PC - perímetro da canela.

AC - withers height; $A G$ - croup height; ACos - chest depth; CC - body length; CG - croup length; CDL - back-loins length; CE - shoulder length; CP - neck length; Ccab - head length; LA - hips width; LP - chest width; DCS - distance between elbow and floor; DSJ - distance between stifle and hock; DJaB - distance between hock and fetlock; PT - chest girth; PA - forearm girth; PJ - knee girth; PB - fetlock girth; PC - cannon girth.

lanço o fator que possuía as medidas de comprimento da cabeça e do pescoço com os maiores pesos fatoriais, entretanto, julga-se necessário haver uma medida na porção posterior dos animais para que realmente haja um ponto de equilíbrio.

Nas potras com seis meses de idade, foram avaliados sete fatores. O primeiro, foi denominado perímetro e relacionou positivamente as variáveis de perímetro do boleto e perímetro da canela, além da variável perímetro do joelho, com peso fatorial próximo a 0,5 . O segundo fator não foi identificado, por apresentar muitas variáveis com elevados pesos fatoriais. O fator $\mathrm{F} 3$, nas potras, foi denominado Carga e apresentou as variáveis comprimento da garupa e do dorso-lombo com elevados pesos fatoriais e de sinais contrários, o que indica correlação negativa entre estas medidas. Logo, as potras aos seis meses de idade com maiores comprimentos de garupa também apresentaram menores comprimentos de dorso-lombo. A associação dessas duas medidas, na forma descrita, é interessante para o melhoramento da raça, pois, garupas maiores estão associadas à maior capacidade de gerar força para o deslocamento, assim como dorso-lombo mais curto está relacionado à menor ocorrência de problemas osteoligamentares nesta região. O contrário, ou seja, garupa curta e dorso-lombo comprido é pouco desejável por razões contrárias às relacionadas acima.

$\mathrm{O}$ fator $\mathrm{F} 4$ foi denominado resistência, pois relacionou de forma direta a largura do peito com o perímetro do antebraço e com comprimento da cabeça. Todas as características apresentaram peso fatorial negativo. Logo, conforme aumentou a largura do peito, houve aumento proporcional no perímetro do antebraço e do comprimento da cabeça.

Andrade (1986) relata que deve existir equilíbrio entre tórax e membros anteriores, pois um tórax excessivamente largo pode determinar menor resis- 
Tabela 4 - Pesos fatoriais e comunalidades (C) das medidas lineares de potras com seis meses de idade Table 4 - Factorial weight and comunalities (C) from linear measures in fillies with six months age

\begin{tabular}{|c|c|c|c|c|c|c|c|c|}
\hline \multirow{4}{*}{$\begin{array}{l}\text { Variável } \\
\text { Measure }\end{array}$} & \multirow{4}{*}{$\mathrm{C}$} & \multicolumn{5}{|c|}{$\begin{array}{l}\text { Fator } \\
\text { Factor }\end{array}$} & \multirow{4}{*}{$\begin{array}{c}\text { F6 } \\
\text { Equilíbrio } \\
\text { Equilibrium }\end{array}$} & \multirow{4}{*}{$\begin{array}{c}\mathrm{F} 7 \\
\text { Rendimento } \\
\text { Eficiency }\end{array}$} \\
\hline & & $\mathrm{F} 1$ & $\mathrm{~F} 2$ & F3 & $\mathrm{F} 4$ & F5 & & \\
\hline & & Perímetro & $?$ & Carga & Resistência & Sustentação & & \\
\hline & & Girth & & Weight & Endurance & Sustentation & & \\
\hline $\mathrm{AC}$ & 0,91475 & 0,14659 & 0,53953 & $-0,15885$ & $-0,29449$ & 0,67835 & $-0,15866$ & 0,06983 \\
\hline $\mathrm{AG}$ & 0,91178 & 0,14505 & 0,55419 & 0,06133 & $-0,26832$ & 0,70672 & $-0,08799$ & 0,02562 \\
\hline ACOS & 0,87465 & 0,13275 & $-0,03029$ & 0,04490 & $-0,07589$ & 0,73510 & $-0,30578$ & 0,46311 \\
\hline $\mathrm{CC}$ & 0,76880 & 0,32173 & 0,56110 & $-0,01853$ & $-0,40663$ & 0,34185 & 0,03586 & 0,25811 \\
\hline CG & 0,84036 & 0,18564 & 0,52862 & $-0,60602$ & $-0,24558$ & 0,24475 & $-0,19687$ & 0,01498 \\
\hline $\mathrm{CDL}$ & 0,90618 & $-0,00971$ & 0,19418 & 0,92188 & $-0,03653$ & 0,10552 & 0,00497 & $-0,07761$ \\
\hline $\mathrm{CE}$ & 0,82953 & $-0,02546$ & 0,16059 & $-0,08390$ & $-0,05374$ & 0,09087 & 0,08646 & 0,88172 \\
\hline $\mathrm{CP}$ & 0,92427 & 0,07410 & 0,14062 & $-0,07770$ & $-0,18443$ & 0,18141 & $-0,90479$ & $-0,08599$ \\
\hline $\mathrm{CCAB}$ & 0,79096 & 0,38093 & 0,26542 & $-0,06075$ & $-0,69303$ & 0,21322 & $-0,08424$ & 0,19715 \\
\hline LA & 0,72815 & 0,23342 & 0,64254 & 0,12966 & $-0,37008$ & 0,29152 & $-0,04065$ & $-0,14281$ \\
\hline $\mathrm{LP}$ & 0,79485 & 0,14384 & 0,24680 & $-0,07874$ & $-0,79588$ & 0,21708 & $-0,09301$ & 0,13362 \\
\hline DCS & 0,79998 & $-0,00261$ & 0,56371 & $-0,33732$ & $-0,32124$ & 0,42146 & $-0,17333$ & 0,23990 \\
\hline DSJ & 0,86445 & $-0,10330$ & 0,87196 & 0,26532 & $-0,09359$ & 0,09771 & 0,06702 & $-0,01620$ \\
\hline $\mathrm{DjaB}$ & 0,79280 & 0,15624 & 0,79391 & $-0,12172$ & $-0,01164$ & $-0,06313$ & $-0,21210$ & 0,27234 \\
\hline PT & 0,67679 & 0,23992 & 0,12589 & 0,07752 & $-0,36305$ & 0,64241 & $-0,21056$ & $-0,09245$ \\
\hline PA & 0,78817 & 0,02420 & 0,02242 & 0,05755 & $-0,67250$ & 0,36471 & $-0,20061$ & $-0,39782$ \\
\hline PJ & 0,78119 & 0,43766 & 0,07710 & $-0,02510$ & $-0,29855$ & 0,66763 & 0,21684 & $-0,03452$ \\
\hline PB & 0,90261 & 0,85680 & 0,04595 & $-0,13056$ & $-0,19196$ & 0,33127 & $-0,02012$ & 0,04846 \\
\hline $\mathrm{PC}$ & 0,87742 & 0,91119 & 0,12053 & 0,02522 & $-0,11256$ & 0,08737 & $-0,09785$ & $-0,04589$ \\
\hline \multicolumn{2}{|c|}{$\begin{array}{l}\text { Explicação } \\
\text { Explication }\end{array}$} & 0,42162 & 0,10556 & 0,08964 & 0,06997 & 0,06249 & 0,04486 & 0,03574 \\
\hline
\end{tabular}

AC - altura na cernelha; AG - altura na garupa; Acos - altura do costado; CC - comprimento do corpo; CG - comprimento da garupa; CDL - comprimento do dorso-lombo; CE - comprimento da escápula; CP - comprimento do pescoço; Ccab - comprimento da cabeça; LA - largura da anca; LP - largura do peito; DCS - distância do codilho ao solo; DSJ - distância da soldra ao jarrete; DjaB - distância do jarrete ao boleto; PT - perímetro torácico; PA - perímetro do antebraço; PJ - perímetro do joelho; PB - perímetro do boleto; PC - perímetro da canela.

$A C$ - withers height; $A G$ - croup height; $A C$ Cos - chest depth; $C C$ - body length; $C G$ - croup length; $C D L$ - back-loins length; $C E$ - shoulder length; $C P$ - neck length; Ccab - head length; LA - hips width; LP - chest width; DCS - distance between elbow and floor; DSJ - distance between stifle and hock; DJaB - distance between hock and fetlock; PT - chest girth; PA - forearm girth; PJ - knee girth; PB - fetlock girth; PC - cannon girth.

tência física e tornar o animal propenso a tropeços. Considerando que a cabeça é uma estrutura importante para o equilíbrio, pode-se denominar este fator resistência, pois, quanto maior a amplitude do tórax, maior a possibilidade de desenvolvimento do sistema respiratório e, conseqüentemente, maior a capacidade para o trabalho e a atividade física, desde que acompanhada de um bom desenvolvimento dos membros anteriores. A amplitude do tórax, associada a um bom equilíbrio, proporcionado pelo desenvolvimento adequado da cabeça, possibilitaria ao animal a resistência necessária para atividades de longa duração.

O fator F5 foi denominado sustentação e as razões são as mesmas descritas nas classes anteriores. O fator F6 foi denominado equilíbrio e apresentou apenas o comprimento do pescoço com elevado peso fatorial, o que indica baixa correlação desta medida com as demais, em potras de seis meses de idade. O fator F7 foi denominado rendi- mento, em virtude do comprimento da escápula, que é uma medida importante para o deslocamento e está relacionada diretamente à amplitude do andamento dos membros anteriores.

Nas Tabelas 5 e 6, podem ser observados os pesos fatoriais e as comunalidades de cada variável em relação aos fatores estudados nos potros e potras com doze meses de idade, respectivamente. Os fatores foram semelhantes aos descritos anteriormente, salvo as posições de localização dos fatores. Os fatores F3 e F5 não foram identificados, o F3 por apresentar elevado número de pesos fatoriais altamente significativos, sem sentido lógico, e o quinto fator, por correlacionar as medidas de distância da soldra ao jarrete com o perímetro do boleto, correlação não observada nos demais grupos.

Nas potras, o segundo fator apresentou muitos pesos fatoriais significativos sem a possibilidade de interpretação lógica, logo, não foi possível identificá-lo. 
Tabela 5 - Pesos fatoriais e comunalidades (C) das medidas lineares de potros com doze meses de idade Table 5 - Factorial weight and comunalities (C) from linear measures in colts with twelve months age

\begin{tabular}{|c|c|c|c|c|c|c|}
\hline \multirow{4}{*}{$\begin{array}{l}\text { Variáveis } \\
\text { Measures }\end{array}$} & \multirow{4}{*}{$\mathrm{C}$} & \multicolumn{5}{|c|}{$\begin{array}{l}\text { Fator } \\
\text { Factor }\end{array}$} \\
\hline & & $\mathrm{F} 1$ & F2 & $\mathrm{F} 3$ & $\mathrm{~F} 4$ & F5 \\
\hline & & Sustentação & Equilíbrio & $?$ & Rendimento & $?$ \\
\hline & & Sustentation & Equilibrium & & Efficiency & \\
\hline $\mathrm{AC}$ & 0,94450 & 0,25716 & 0,15113 & 0,60207 & 0,49401 & 0,49900 \\
\hline $\mathrm{AG}$ & 0,90563 & 0,20426 & 0,13193 & 0,68892 & 0,36753 & 0,48664 \\
\hline $\mathrm{ACOS}$ & 0,91820 & 0,66924 & 0,11172 & 0,30002 & 0,59868 & 0,09699 \\
\hline $\mathrm{CC}$ & 0,78402 & 0,54434 & $-0,02262$ & 0,56986 & 0,32965 & 0,23191 \\
\hline CG & 0,71671 & 0,33471 & 0,27982 & 0,66194 & $-0,22597$ & $-0,19276$ \\
\hline CDL & 0,82903 & 0,04958 & 0,16169 & 0,89324 & $-0,01282$ & 0,04882 \\
\hline $\mathrm{CE}$ & 0,89444 & 0,33324 & 0,12388 & 0,03861 & 0,87485 & 0,03455 \\
\hline $\mathrm{CP}$ & 0,84007 & 0,16723 & 0,79926 & 0,21050 & 0,31548 & 0,17159 \\
\hline CCAB & 0,71243 & 0,43694 & 0,54986 & 0,13188 & 0,42731 & 0,13849 \\
\hline LA & 0,88483 & 0,91976 & 0,08845 & $-0,01145$ & 0,17583 & $-0,00092$ \\
\hline LP & 0,82042 & 0,68625 & 0,12978 & 0,42282 & 0,09231 & 0,38125 \\
\hline DCS & 0,82471 & 0,05441 & 0,08283 & 0,52651 & 0,57723 & 0,45220 \\
\hline DSJ & 0,84522 & 0,11976 & 0,07958 & 0,07581 & 0,13527 & 0,89471 \\
\hline DjaB & 0,78281 & 0,11463 & 0,17098 & 0,01697 & 0,84054 & 0,18343 \\
\hline PT & 0,90624 & 0,73775 & 0,16508 & 0,35270 & 0,44666 & 0,10401 \\
\hline PA & 0,77354 & 0,30034 & $-0,53392$ & $-0,08049$ & 0,49152 & 0,38756 \\
\hline PJ & 0,73656 & 0,50536 & $-0,15994$ & 0,42789 & 0,45369 & 0,25820 \\
\hline PB & 0,77452 & 0,66297 & 0,05166 & 0,23459 & 0,06595 & 0,52244 \\
\hline $\mathrm{PC}$ & 0,76481 & 0,37306 & $-0,17098$ & 0,58340 & 0,25051 & 0,43965 \\
\hline $\begin{array}{l}\text { Explica } \\
\text { Explica }\end{array}$ & & 0,51242 & 0,10700 & 0,08435 & 0,07486 & 0,04551 \\
\hline
\end{tabular}

AC - altura na cernelha; AG - altura na garupa; Acos - altura do costado; CC - comprimento do corpo; CG - comprimento da garupa; CDL - comprimento do dorso-lombo; CE - comprimento da escápula; CP - comprimento do pescoço; Ccab - comprimento da cabeça; LA - largura da anca; LP - largura do peito; DCS - distância do codilho ao solo; DSJ - distância da soldra ao jarrete; DjaB - distância do jarrete ao boleto; PT - perímetro torácico; PA - perímetro do antebraço; PJ - perímetro do joelho; PB - perímetro do boleto; PC - perímetro da canela.

AC - withers height; $A G$ - croup height; ACos - chest depth; CC - body length; CG - croup length; CDL - back-loins length; CE - shoulder length; CP - neck length; Ccab - head length; LA - hips width; LP - chest width; DCS - distance between elbow and floor; DSJ - distance between stifle and hock; DJaB - distance between hock and fetlock; PT - chest girth; PA - forearm girth; PJ - knee girth; PB - fetlock girth; PC - cannon girth

O terceiro fator apresentou nova combinação, até então não observada, entre as medidas de largura do peito e distância da soldra ao jarrete, que não apresentou sentido que não justificou a classificação do fator. O quarto fator novamente apresentou a variável distância do jarrete ao boleto de forma isolada, não sendo possível identificá-lo. Os demais fatores foram descritos em outras idades.

Nas Tabelas 7 e 8, encontram-se as comunalidades e os pesos fatoriais das medidas angulares de potros e potras recém-nascidos da raça Mangalarga Marchador, respectivamente. Foram necessários, respectivamente, sete e seis fatores para explicar um percentual mínimo de $80 \%$ da variação total. Os valores das comunalidades foram geralmente altos, com exceção apenas para o ângulo metatarsofalangeano, nos potros, de $61,42 \%$, o que indica que os fatores selecionados explicam bem a variação das características estudadas.
$\mathrm{O}$ fator $\mathrm{F} 1$ dos potros foi denominado comodidade e teve os ângulos falange-solo-anterior e posterior com os maiores pesos fatoriais, ambos negativos. Estas angulações determinam as inclinações das quartelas anteriores e posteriores, que, em associação com os momentos de tríplice apoio e com adequadas inclinações da escápula com a horizontal, conferem mais suavidade ao andamento. No fator F2, os ângulos metacarpo e metatarsofalangeano apresentaram os maiores pesos fatoriais e foram diretamente correlacionados, logo variações em um deles são acompanhadas de variações semelhantes no outro. Segundo Andrade (1984), a região do boleto é responsável pela elasticidade dos movimentos, considerações que classificaram o fator como agilidade.

$\mathrm{O}$ fator $\mathrm{F} 3$ apresentou os ângulos escápulo-solo e tíbio-metatarsiano com os maiores pesos fatoriais. Os sinais contrários dos pesos fatoriais indicam cor- 
Tabela 6 - Pesos fatoriais e comunalidades (C) das medidas lineares de potras com doze meses de idade. Table 6 - Factorial weight and comunalities (C) from linear measures in fillies with twelve months age.

\begin{tabular}{|c|c|c|c|c|c|c|}
\hline \multirow{4}{*}{$\begin{array}{l}\text { Variável } \\
\text { Measure }\end{array}$} & \multirow{4}{*}{$\mathrm{C}$} & \multicolumn{5}{|c|}{$\begin{array}{l}\text { Fator } \\
\text { Factor }\end{array}$} \\
\hline & & $\mathrm{F} 1$ & $\mathrm{~F} 2$ & F3 & $\mathrm{F} 4$ & F5 \\
\hline & & Sustentação & $?$ & $?$ & $?$ & Carga \\
\hline & & Sustentation & & & & Weight \\
\hline$\overline{\mathrm{AC}}$ & 0,92140 & 0,85567 & $-0,29921$ & $-0,28289$ & 0,10130 & $-0,09702$ \\
\hline $\mathrm{AG}$ & 0,94713 & 0,90789 & $-0,29011$ & $-0,15706$ & 0,08380 & $-0,08371$ \\
\hline ACOS & 0,75066 & 0,27676 & $-0,80184$ & 0,15042 & $-0,04272$ & $-0,08163$ \\
\hline $\mathrm{CC}$ & 0,71331 & 0,61930 & $-0,48642$ & $-0,17440$ & $-0,08667$ & $-0,23507$ \\
\hline CG & 0,83325 & 0,18877 & $-0,12563$ & $-0,18327$ & 0,08389 & $-0,86093$ \\
\hline $\mathrm{CDL}$ & 0,70206 & 0,54440 & $-0,12242$ & 0,08918 & $-0,47188$ & $-0,40010$ \\
\hline $\mathrm{CE}$ & 0,69710 & 0,54783 & $-0,55397$ & $-0,24740$ & 0,00265 & $-0,16996$ \\
\hline $\mathrm{CP}$ & 0,68470 & 0,45359 & $-0,45405$ & $-0,44096$ & $-0,26875$ & $-0,07826$ \\
\hline $\mathrm{CCAB}$ & 0,78544 & 0,20049 & $-0,69468$ & $-0,43675$ & 0,22089 & $-0,15206$ \\
\hline LA & 0,76773 & 0,22635 & $-0,76399$ & $-0,17723$ & $-0,10533$ & $-0,30053$ \\
\hline $\mathrm{LP}$ & 0,85899 & 0,29737 & $-0,69451$ & $-0,52647$ & $-0,08495$ & $-0,06192$ \\
\hline DCS & 0,77983 & 0,84855 & 0,01123 & $-0,09881$ & 0,10757 & $-0,19580$ \\
\hline DSJ & 0,77689 & 0,26776 & 0,00871 & $-0,81557$ & $-0,12582$ & $-0,15535$ \\
\hline $\mathrm{DjaB}$ & 0,84162 & 0,21066 & $-0,14055$ & 0,16034 & 0,85917 & $-0,11666$ \\
\hline PT & 0,90014 & 0,73973 & $-0,57562$ & $-0,14573$ & $-0,00905$ & $-0,01689$ \\
\hline PA & 0,87051 & $-0,20069$ & $-0,64252$ & $-0,49366$ & 0,41311 & $-0,05519$ \\
\hline PJ & 0,79277 & 0,58736 & $-0,54956$ & 0,17855 & 0,25116 & 0,22538 \\
\hline PB & 0,81942 & 0,50712 & $-0,58739$ & $-0,16060$ & 0,39285 & 0,19258 \\
\hline $\mathrm{PC}$ & 0,80141 & 0,21012 & $-0,81965$ & 0,05188 & 0,28141 & 0,05950 \\
\hline \multicolumn{2}{|c|}{$\begin{array}{l}\text { Explicação } \\
\text { Explication }\end{array}$} & 0,48881 & 0,11735 & 0,09151 & 0,05790 & 0,04678 \\
\hline
\end{tabular}

Tabela 7 - Pesos fatoriais e comunalidades (C) das medidas angulares de potros recém-nascidas Table 7 - Factorial weight and comunalities (C) from angular measures in newly born colts

\begin{tabular}{|c|c|c|c|c|c|c|c|c|}
\hline & \multirow[b]{2}{*}{$\mathrm{C}$} & \multicolumn{7}{|c|}{$\begin{array}{l}\text { Fator } \\
\text { Factor }\end{array}$} \\
\hline & & $\begin{array}{c}\mathrm{F} 1 \\
\text { Comodidade } \\
\text { Confortableness }\end{array}$ & $\begin{array}{c}\mathrm{F} 2 \\
\text { Agilidade } \\
\text { Agility }\end{array}$ & $\begin{array}{c}\mathrm{F} 3 \\
\text { Rendimento } \\
\text { Efficiency }\end{array}$ & $\begin{array}{c}\mathrm{F} 4 \\
\text { Impulsão } \\
\text { Impulsion }\end{array}$ & $\begin{array}{c}\mathrm{F} 5 \\
?\end{array}$ & $\begin{array}{c}\text { F6 } \\
\text { Força } \\
\text { Force }\end{array}$ & $\begin{array}{c}\text { F7 } \\
\text { Analogia } \\
\text { Analogy }\end{array}$ \\
\hline$\overline{\mathrm{AES}}$ & 0.88591 & 0,02541 & 0,03557 & 0,90280 & 0,16308 & 0,09631 & 0,14952 & 0,10353 \\
\hline $\mathrm{AEU}$ & 0.92815 & 0,01293 & 0,01501 & 0,05441 & $-0,03188$ & 0,95821 & 0,05228 & 0,05368 \\
\hline AUR & 0.93494 & 0,08938 & 0,19228 & $-0,01744$ & $-0,06254$ & 0,05146 & 0,02264 & 0,93947 \\
\hline $\mathrm{AMcF}$ & 0.76061 & $-0,11248$ & $-0,85820$ & $-0,04712$ & 0,04169 & 0,06844 & 0,03009 & $-0,04359$ \\
\hline AFSA & 0.83352 & $-0,86571$ & $-0,09557$ & $-0,08648$ & $-0,04302$ & 0,14366 & $-0,21037$ & $-0,02663$ \\
\hline ACS & 0.85292 & $-0,06015$ & $-0,35987$ & 0,13951 & 0,78281 & $-0,22870$ & $-0,14759$ & $-0,11602$ \\
\hline $\mathrm{ACF}$ & 0.79944 & 0,18222 & 0,33073 & $-0,10572$ & 0,68032 & 0,23528 & 0,35004 & 0,07042 \\
\hline AFT & 0.95235 & 0,07763 & $-0,03479$ & 0,05354 & 0,03235 & 0,04690 & 0,96835 & 0,03614 \\
\hline ATM & 0.81373 & $-0,05116$ & $-0,18652$ & $-0,67336$ & 0,29358 & 0,08010 & 0,21399 & 0,42955 \\
\hline $\mathrm{AMtF}$ & 0.61418 & 0,32901 & $-0,66670$ & $-0,11634$ & 0,04315 & $-0,11899$ & $-0,00378$ & $-0,17855$ \\
\hline AFSP & 0.83178 & $-0,87352$ & 0,16129 & 0,02076 & $-0,00643$ & $-0,17235$ & 0,08239 & $-0,07586$ \\
\hline \multicolumn{2}{|c|}{$\begin{array}{l}\text { Explicação } \\
\text { Explication }\end{array}$} & 0,18115 & 0,16560 & 0,13538 & 0,11628 & 0,09447 & 0,07688 & 0,06729 \\
\hline
\end{tabular}

AES - ângulo escápulo-solo; AEU - ângulo escápulo-umeral; AUR - ângulo úmero-radial; AMcF - ângulo Metacarpo-falangeano; AFSA - ângulo falange-solo anterior; ACS - ângulo coxal-solo; ACF - ângulo coxofemoral; AFT - ângulo fêmur-tibial; ATM - ângulo tíbiometatarsiano; AMtF - ângulo metatarso-falangeano; AFSP - ângulo falange-solo posterior.

AES - shoulder-floor angle; AEU - shoulder-humerus angle; AUR-humerus-radio angle; AMcF-metacarpal-phalanx angle; $A F S A$ - phalanx-floor-anterior angle; ACS - coxae-floor angle; ACF - coxae-femur angle; AFT tibia-femur angle; ATM - tibia-metatarsal angle; AMtF - metatarsal-phalanx angle; AFSP - phalanxfloor-posterior angle.

\section{R. Bras. Zootec., v.34, n.2, p.613-626, 2005}


Tabela 8 - Pesos fatoriais e comunalidades $(C)$ das medidas angulares de potras recém-nascidas, da raça Mangalarga Marchador

Table 8 - Factorial weight and comunalities (C) from angular measures in newly born fillies

\begin{tabular}{|c|c|c|c|c|c|c|c|}
\hline & \multicolumn{7}{|c|}{$\begin{array}{l}\text { Fator } \\
\text { Factor }\end{array}$} \\
\hline & $\mathrm{C}$ & $\begin{array}{c}1 \\
\text { Amplitude } \\
\text { Amplitude }\end{array}$ & $\begin{array}{c}2 \\
\text { Altura } \\
\text { Height }\end{array}$ & $\begin{array}{l}3 \\
?\end{array}$ & $\begin{array}{c}4 \\
\text { Perímetro } \\
\text { Girth }\end{array}$ & $\begin{array}{c}5 \\
\text { Equilíbrio } \\
\text { Equilibrium }\end{array}$ & $\begin{array}{l}6 \\
?\end{array}$ \\
\hline$\overline{\mathrm{AC}}$ & 0,9121 & 0,52464 & 0,66123 & 0,37469 & 0,09051 & 0,00683 & 0,22594 \\
\hline $\mathrm{AG}$ & 0,8780 & 0,50077 & 0,65247 & 0,34465 & 0,03783 & 0,03929 & 0,28251 \\
\hline ACOS & 0,8361 & 0,68480 & 0,21581 & 0,48354 & $-0,10491$ & 0,04149 & 0,27214 \\
\hline $\mathrm{CC}$ & 0,8280 & 0,73087 & 0,25736 & 0,38368 & 0,15812 & 0,20270 & 0,11963 \\
\hline CG & 0,8176 & 0,77889 & $-0,03370$ & 0,24307 & 0,25776 & 0,18154 & 0,22660 \\
\hline CDL & 0,7690 & 0,05805 & $-0,13667$ & 0,77982 & 0,28949 & 0,23335 & 0,02511 \\
\hline $\mathrm{CE}$ & 0,8196 & 0,35111 & 0,23976 & 0,74721 & 0,06055 & 0,27177 & 0,05515 \\
\hline $\mathrm{CP}$ & 0,8256 & 0,35720 & 0,15546 & 0,32096 & $-0,00570$ & 0,69432 & 0,29797 \\
\hline $\mathrm{CCAB}$ & 0,7472 & 0,24893 & 0,30432 & 0,74957 & 0,15451 & 0,08272 & 0,01036 \\
\hline LA & 0,7510 & 0,66061 & 0,24115 & 0,43220 & 0,25057 & 0,03692 & 0,07440 \\
\hline $\mathrm{LP}$ & 0,9144 & 0,47366 & $-0,07703$ & 0,72173 & 0,02910 & $-0,36384$ & 0,17343 \\
\hline DCS & 0,8092 & 0,25918 & 0,69005 & 0,17424 & $-0,03658$ & 0,38396 & 0,29572 \\
\hline DSJ & 0,9025 & 0,08054 & 0,34616 & 0,03764 & 0,12454 & 0,17817 & 0,85299 \\
\hline DjaB & 0,8458 & $-0,00008$ & 0,86565 & $-0,10076$ & 0,28440 & $-0,00512$ & 0,07377 \\
\hline PT & 0,8897 & 0,78784 & 0,17271 & 0,44132 & 0,14941 & $-0,02276$ & 0,14699 \\
\hline PA & 0,8214 & 0,86137 & 0,15350 & $-0,03929$ & 0,13671 & 0,16994 & $-0,08271$ \\
\hline PJ & 0,8398 & 0,69167 & 0,24545 & 0,18952 & 0,50847 & 0,06153 & $-0,05388$ \\
\hline PB & 0,8638 & 0,34630 & 0,25350 & 0,24597 & 0,74581 & $-0,04424$ & 0,24693 \\
\hline $\mathrm{PC}$ & 0,7459 & 0,50386 & 0,15320 & 0,42953 & 0,52535 & 0,04016 & $-0,08036$ \\
\hline $\begin{array}{l}\operatorname{Exp} \\
\operatorname{Exp}\end{array}$ & & 0,53197 & 0,10724 & 0,06884 & 0,05276 & 0,03854 & 0,03320 \\
\hline
\end{tabular}

AES - ângulo escápulo-solo; AEU - ângulo escápulo-umeral; AUR - ângulo úmero-radial; AMcF - ângulo Metacarpo-falangeano; AFSA - ângulo falange-solo anterior; ACS - ângulo coxal-solo; ACF - ângulo coxofemoral; AFT - ângulo fêmur-tibial; ATM - ângulo tíbiometatarsiano; AMtF - ângulo metatarso-falangeano; AFSP - ângulo falange-solo posterior.

AES - shoulder-floor angle; $A E U$ - shoulder-humerus angle; AUR - humerus-radio angle; AMCF-metacarpal-phalanx angle; AFSA - phalanx-floor-anterior angle; ACS - coxae-floor angle; ACF - coxae-femur angle; AFT tibia-femur angle; ATM - tibia-metatarsal angle; AMtF - metatarsal-phalanx angle; AFSP - phalanxfloor-posterior angle.

relação negativa entre essas duas medidas; portanto, à medida que a abertura de um desses ângulos diminuiu, houve aumento relativamente proporcional do outro. O fator foi denominado rendimento em razão da angulação da escápula estar envolvida na flexão do braço e antebraço, ou seja, está relacionada à amplitude da passada dos membros anteriores e atua no amortecimento do impacto do peso do animal ao tocar o solo, durante o andamento. O ângulo tíbiometatarsiano, também conhecido como angulação de jarrete, está diretamente envolvido na amplitude do andamento dos membros posteriores. Além disso é um ângulo de abertura anterior, logo está relacionado à geração de força para o deslocamento da massa corpórea.

O fator F4 apresentou os ângulos coxal-solo e coxofemoral com os maiores pesos fatoriais e estiveram diretamente correlacionados, o que significa que à medida que reduz a inclinação da garupa, reduz também o ângulo coxofemoral, o que é, indubitavelmente, um dos principais ângulos de abertura anterior e está associado à musculatura de garupa, cuja contração produz a força necessária ao deslocamento corporal, sendo, por este motivo, denominado impulsão.

$\mathrm{O}$ fator F5 nos potros apresentou apenas o ângulo escápulo-umeral com elevado peso fatorial, o que indica a baixa correlação desta medida com as demais avaliadas. Este ângulo está envolvido na flexão do braço e do antebraço, estruturas importantes na evolução do andamento e na amplitude da passada dos membros anteriores.

$\mathrm{O}$ fator $\mathrm{F} 6$ nos potros foi denominado força e teve a medida do ângulo fêmur-tibial como principal peso fatorial e, por estar isolado neste fator, indica a baixa correlação desta medida com as demais nesta idade. 
Este ângulo está envolvido na musculatura dos membros posteriores e, portanto, está relacionado à força gerada por estes músculos durante o movimento. $\mathrm{O}$ ângulo fêmur-tibial apresenta abertura em direção ao posterior do animal. Segundo Ribeiro (1988), ângulos com este tipo de abertura são chamados de complementares ou de ligação, enquanto aqueles de abertura voltada para o anterior, como o tíbio-metatarsiano, estão envolvidos com os movimentos, sendo chamados de impulsores.

O fator F7, nos potros, foi denominado analogia e apresentou os ângulos úmero-radial e tíbiometatarsiano com os maiores pesos fatoriais. Os sinais diferentes, nos pesos fatoriais destes dois ângulos, indicam correlação negativa entre eles; à medida que a abertura de um destes ângulos aumentou, a do outro diminuiu.

São ângulos de abertura anterior e estão diretamente relacionados à impulsão para o movimento, relação descrita por Ribeiro (1988) como uma analogia de direção e funcionamento de certas angulações do membro anterior com as de membro posterior.

$\mathrm{O}$ fator F1 nas potras foi denominado amplitude e não foi encontrado entre os potros. Este fator teve os ângulos escápulo-umeral, úmero-radial e fêmur- tibial com os pesos fatoriais mais elevados. Os dois primeiros ângulos estão envolvidos na flexão do braço e do antebraço, estando relacionados com a amplitude do andamento dos membros anteriores, enquanto o fêmur-tibial é um ângulo de ligação e está mais envolvido na contração da musculatura dos membros posteriores. Os fatores F2 e F3 foram denominados agilidade e comodidade, respectivamente, e tiveram as mesmas características dos fatores agilidade e comodidade observados nos potros nesta idade.

$\mathrm{O}$ fator $\mathrm{F} 4$ não foi identificado, sendo caracterizado pela medida do ângulo tibío-metatarsiano, com pouca correlação com as demais medidas. O fator F5 das potras foi denominado impulsão e também foi observado nos potros, entretanto na quarta posição. O fator F6 nas potras foi denominado rendimento e foi observado na terceira posição entre os potros desta faixa etária, sendo caracterizado pelo elevado peso fatorial do ângulo escápulo-solo, o que indica a baixa correlação desta medida com as demais nas potras desta faixa etária.

Nas Tabelas 9 e 10, estão as comunalidades e os pesos fatoriais das medidas angulares de potros e potras da raça Mangalarga Marchador com seis meses de idade, respectivamente.

Nos potros, foram observados seis fatores, todos

Tabela 9 - Pesos fatoriais e comunalidades $(C)$ das medidas angulares de potros com seis meses de idade, da raça Mangalarga Marchador

Table 9 - Factorial weight and comunalities (C) from angular measures in colts with six months age

\begin{tabular}{|c|c|c|c|c|c|c|c|}
\hline & \multirow[b]{2}{*}{$\mathrm{C}$} & \multicolumn{5}{|c|}{$\begin{array}{l}\text { Fator } \\
\text { Factor }\end{array}$} & \multirow[b]{2}{*}{$\begin{array}{c}\text { F6 } \\
\text { Agilidade } \\
\text { Agility } \\
\end{array}$} \\
\hline & & $\begin{array}{c}\mathrm{F} 1 \\
\text { Rendimento } \\
\text { Efficiency }\end{array}$ & $\begin{array}{c}\mathrm{F} 2 \\
\text { Impulsão } \\
\text { Impulsion }\end{array}$ & $\begin{array}{c}\text { F3 } \\
\text { Comodidade } \\
\text { Confortableness }\end{array}$ & $\begin{array}{c}\mathrm{F} 4 \\
\text { Analogia } \\
\text { Analogy }\end{array}$ & $\begin{array}{c}\text { F5 } \\
\text { Amplitude } \\
\text { Amplitude }\end{array}$ & \\
\hline AES & 0,82182 & $-0,71721$ & $-0,14804$ & 0,46957 & 0,13474 & $-0,20551$ & $-0,06804$ \\
\hline AEU & 0,76242 & 0,01571 & 0,35466 & $-0,10800$ & 0,30107 & $-0,70851$ & $-0,17915$ \\
\hline AUR & 0,84420 & $-0,19003$ & 0,30801 & $-0,31991$ & 0,65830 & $-0,09811$ & $-0,40974$ \\
\hline $\mathrm{AmcF}$ & 0,85211 & $-0,67401$ & 0,01148 & $-0,16492$ & $-0,03925$ & 0,45523 & 0,40213 \\
\hline AFSA & 0,75894 & $-0,05449$ & 0,02920 & 0,84915 & 0,09458 & 0,13148 & $-0,08852$ \\
\hline ACS & 0,82963 & $-0,09725$ & $-0,86993$ & $-0,05601$ & 0,16938 & 0,17541 & 0,02814 \\
\hline $\mathrm{ACF}$ & 0,90809 & 0,00365 & $-0,89732$ & $-0,03431$ & $-0,10702$ & $-0,25128$ & $-0,16466$ \\
\hline AFT & 0,74434 & 0,00446 & $-0,28889$ & 0,03612 & $-0,27526$ & $-0,76042$ & $-0,07455$ \\
\hline ATM & 0,87747 & $-0,00750$ & 0,23013 & $-0,20583$ & $-0,83806$ & $-0,09493$ & $-0,26595$ \\
\hline $\mathrm{AmtF}$ & 0,92601 & $-0,10318$ & 0,12809 & 0,09105 & 0,09299 & 0,16086 & 0,92528 \\
\hline FSP & 0,64048 & $-0,06158$ & 0,06147 & 0,75165 & $-0,07277$ & $-0,09691$ & 0,23074 \\
\hline & & 0,20690 & 0,18509 & 0,15007 & 0,12952 & 0,07466 & 0,06882 \\
\hline
\end{tabular}

AES - ângulo escápulo-solo; AEU - ângulo escápulo-umeral; AUR - ângulo úmero-radial; AMcF - ângulo Metacarpo-falangeano; AFSA - ângulo falange-solo anterior; ACS - ângulo coxal-solo; ACF - ângulo coxofemoral; AFT - ângulo fêmur-tibial; ATM - ângulo tíbiometatarsiano; AMtF - ângulo metatarso-falangeano; AFSP - Ângulo falange-solo posterior.

AES - shoulder-floor angle; AEU - shoulder-humerus angle; AUR - humerus-radio angle; AMcF-metacarpal-phalanx angle; $A F S A$ - phalanx-floor-anterior angle; ACS - coxae-floor angle; ACF - coxae-femur angle; AFT tibia-femur angle; ATM - tibia-metatarsal angle; AMtF - metatarsal-phalanx angle; AFSP - phalanxfloor-posterior angle.

R. Bras. Zootec., v.34, n.2, p.613-626, 2005 
Tabela 10 - Pesos fatoriais e comunalidades $(\mathrm{C})$ das medidas angulares de potras com seis meses de idade, da raça Mangalarga Marchador

Table 10 - Factorial weight and comunalities (C) from angular measures in fillies with six months age

\begin{tabular}{|c|c|c|c|c|c|c|c|}
\hline & \multirow[b]{2}{*}{$\mathrm{C}$} & \multicolumn{5}{|c|}{$\begin{array}{l}\text { Fator } \\
\text { Factor }\end{array}$} & \\
\hline & & $\begin{array}{l}1 \\
?\end{array}$ & $\begin{array}{c}2 \\
\text { Impulsão } \\
\text { Impulsion }\end{array}$ & $\begin{array}{c}3 \\
\text { Força } \\
\text { Force } \\
\end{array}$ & $\begin{array}{l}4 \\
?\end{array}$ & $\begin{array}{c}5 \\
\text { Rendimento } \\
\text { Efficiency } \\
\end{array}$ & $\begin{array}{c}6 \\
\text { Agilidade } \\
\text { Agility }\end{array}$ \\
\hline AES & 0,88708 & 0,09992 & $-0,17452$ & $-0,08991$ & $-0,15903$ & $-0,90097$ & -0.03899 \\
\hline AEU & 0,80613 & $-0,58229$ & $-0,41020$ & $-0,02409$ & $-0,20470$ & $-0,04959$ & 0.50384 \\
\hline AUR & 0,87732 & 0,01207 & 0,20526 & 0,31291 & $-0,85399$ & $-0,08804$ & 0.00888 \\
\hline $\mathrm{AMcF}$ & 0,91120 & 0,00339 & $-0,01476$ & 0,08908 & $-0,08581$ & $-0,06277$ & -0.94432 \\
\hline AFSA & 0,76802 & 0,28753 & $-0,38365$ & $-0,28504$ & $-0,62333$ & $-0,16651$ & -0.20161 \\
\hline ACS & 0,84023 & 0,11255 & 0,89671 & $-0,14724$ & 0,02453 & 0,01111 & 0.03255 \\
\hline $\mathrm{ACF}$ & 0,79368 & $-0,06680$ & 0,81104 & 0,27365 & $-0,07654$ & 0,21820 & -0.05538 \\
\hline AFT & 0,86763 & $-0,07842$ & 0,05513 & 0,90527 & $-0,14441$ & 0,09984 & -0.09005 \\
\hline ATM & 0,81988 & $-0,85662$ & $-0,07653$ & 0,16208 & 0,19321 & 0,10990 & -0.06749 \\
\hline $\mathrm{AMtF}$ & 0,76419 & 0,47987 & $-0,30690$ & 0,08032 & $-0,35063$ & 0,36961 & -0.41680 \\
\hline AFSP & 0,77741 & 0,53510 & $-0,39260$ & 0,40945 & 0,11215 & $-0,35994$ & -0.16478 \\
\hline $\mathrm{E}$ & & 0,23642 & 0,19299 & 0,13197 & 0,10934 & 0,08524 & 0,07248 \\
\hline
\end{tabular}

AES - ângulo escápulo-solo; AEU - ângulo escápulo-umeral; AUR - ângulo úmero-radial; AMcF - ângulo Metacarpo-falangeano; AFSA - ângulo falange-solo anterior; ACS - ângulo coxal-solo; ACF - ângulo coxofemoral; AFT - ângulo fêmur-tibial; ATM - ângulo tíbiometatarsiano; AMtF - ângulo metatarso-falangeano; AFSP - Ângulo falange-solo posterior.

AES - shoulder-floor angle; AEU - shoulder-humerus angle; $A U R$ - humerus-radio angle; $A M c F$ - metacarpal-phalanx angle; $A F S A$ - phalanx-floor-anterior angle; ACS - coxae-floor angle; ACF - coxae-femur angle; AFT tibia-femur angle; ATM - tibia-metatarsal angle; AMtF - metatarsal-phalanx angle; AFSP - phalanxfloor-posterior angle.

descritos nos grupos de recém-nascidos, enquanto, nas potras, o primeiro e o quarto fatores não foram identificados. É importante ressaltar a relação positiva entre os ângulos úmero-radial e falange-soloanterior, no fator F4. Esta relação indica o grande risco que um casqueamento inadequado pode representar para o andamento de animais jovens pois o ângulo úmero-radial possui abertura anterior e está envolvido na impulsão de membros anteriores durante o deslocamento.

Nas Tabelas 11 e 12, constam os valores das comunalidades e dos pesos fatoriais das medidas angulares de potros e potras, respectivamente, com doze meses de idade.

Nos potros com 12 meses de idade, apenas o primeiro fator não foi identificado, pois apresentou pesos fatoriais elevados para diversas variáveis. Nas potras, o quinto e o sexto fatores não foram identificados, uma vez que as variáveis relacionadas não apresentaram significado claro, verificando-se que nem sempre é fácil identificar os fatores, pois muitas vezes as relações não apresentam significado claro.

A análise fatorial é de mais fácil interpretação quando as variáveis em estudo são de pesos fatoriais significativos apenas em um dos fatores sob estudo.
Em muitas situações, foi possível observar que indicando complexa relação entre as medidas corporais dos eqüinos da raça Mangalarga Marchador.

\section{Conclusões}

A análise fatorial foi eficiente em agrupar as medidas lineares e angulares, facilitando a visualização de relações importantes entre as medidas morfométricas, o que pode ser de grande importância a determinação dos atributos de marcha Mangalarga Marchador.

\section{Agradecimento}

À Fundação de Amparo à Pesquisa do Estado do Rio de Janeiro, à Coordenação de Aperfeiçoamento de Pessoal de Nível Superior e à Associação Brasileira de Criadores do Cavalo Mangalarga Marchador, pelo apoio financeiro.

\section{Literatura Citada}

ANDRADE L.S. Criação e adestramento de cavalos marchadores (Breeding and training gaited horses). Recife: 1984.284 p. 
Tabela 11 - Pesos fatoriais e comunalidades $(C)$ das medidas angulares de potros com doze meses de idade, da raça Mangalarga Marchador

Table 11 - Factorial weight and comunalities (C) from angular measures in colts with twelve months age

\begin{tabular}{|c|c|c|c|c|c|c|}
\hline \multirow{5}{*}{$\begin{array}{l}\text { Variável } \\
\text { Measure }\end{array}$} & \multirow{5}{*}{$\mathrm{C}$} & \multicolumn{5}{|c|}{ Fator } \\
\hline & & \multicolumn{5}{|c|}{ Factor } \\
\hline & & $\mathrm{F} 1$ & $\mathrm{~F} 2$ & F3 & F4 & F5 \\
\hline & & $?$ & Comodidade & Analogia & Impulsão & Rendimento \\
\hline & & & Confortableness & Analogy & Impulsion & Efficiency \\
\hline AES & 0,91626 & 0,15340 & 0,12291 & 0,20406 & 0,09650 & $-0,90921$ \\
\hline AEU & 0,75457 & $-0,79892$ & 0,12105 & $-0,28592$ & $-0,06638$ & 0,12444 \\
\hline AUR & 0,84408 & 0,19373 & $-0,21658$ & 0,82681 & 0,17564 & $-0,21254$ \\
\hline $\mathrm{AMcF}$ & 0,91549 & 0,92969 & 0,21221 & $-0,07144$ & 0,01484 & $-0,02845$ \\
\hline AFSA & 0,93518 & 0,12083 & 0,94183 & $-0,05911$ & $-0,16851$ & $-0,04074$ \\
\hline ACS & 0,84843 & 0,17376 & $-0,29315$ & 0,10055 & 0,84729 & $-0,06550$ \\
\hline $\mathrm{ACF}$ & 0,89478 & $-0,56156$ & 0,09431 & $-0,38070$ & 0,62950 & 0,17130 \\
\hline AFT & 0,83925 & $-0,61211$ & 0,35761 & 0,15394 & 0,16634 & 0,53415 \\
\hline ATM & 0,69481 & $-0,11505$ & 0,14294 & 0,80125 & $-0,13687$ & $-0,02013$ \\
\hline $\mathrm{AMtF}$ & 0,81800 & 0,76782 & 0,39793 & $-0,12665$ & 0,05494 & $-0,22591$ \\
\hline FSP & 0,85967 & 0,15608 & 0,60464 & 0,15129 & $-0,35171$ & $-0,56845$ \\
\hline \multicolumn{2}{|c|}{$\begin{array}{l}\text { Explicação } \\
\text { Explication }\end{array}$} & 0,33809 & 0,18769 & 0,15025 & 0,09256 & 0,07872 \\
\hline
\end{tabular}

AES - ângulo escápulo-solo; AEU - ângulo escápulo-umeral; AUR - ângulo úmero-radial; AMcF - ângulo Metacarpo-falangeano; AFSA - ângulo falange-solo anterior; ACS - ângulo coxal-solo; ACF - ângulo coxofemoral; AFT - ângulo fêmur-tibial; ATM - ângulo tíbiometatarsiano; AMtF - ângulo metatarso-falangeano; AFSP - ângulo falange-solo posterior.

AES - shoulder-floor angle; $A E U$ - shoulder-humerus angle; $A U R$ - humerus-radio angle; AMcF- metacarpal-phalanx angle; AFSA - phalanx-floor-anterior angle; ACS - coxae-floor angle; ACF - coxae-femur angle; AFT tibia-femur angle; ATM - tibia-metatarsal angle; AMtF - metatarsal-phalanx angle; AFSP - phalanxfloor-posterior angle.

Tabela 12 - Pesos fatoriais e comunalidades (C) das medidas angulares de potras com doze meses de idade, da raça Mangalarga Marchador

Table 12 - Factorial weight and comunalities (C) from angular measures in fillies with twelve months age

\begin{tabular}{|c|c|c|c|c|c|c|c|}
\hline & \multirow[b]{2}{*}{$\mathrm{C}$} & \multicolumn{4}{|c|}{$\begin{array}{l}\text { Fator } \\
\text { Factor }\end{array}$} & & \multirow[b]{2}{*}{$\begin{array}{l}6 \\
?\end{array}$} \\
\hline & & $\begin{array}{c}1 \\
\text { Amplitude } \\
\text { Amplitude }\end{array}$ & $\begin{array}{c}2 \\
\text { Comodidade } \\
\text { Confortableness }\end{array}$ & $\begin{array}{c}3 \\
\text { Rendimento } \\
\text { Efficiency }\end{array}$ & $\begin{array}{c}4 \\
\text { Força } \\
\text { Force }\end{array}$ & $\begin{array}{l}5 \\
?\end{array}$ & \\
\hline$\overline{\mathrm{AES}}$ & 0,79269 & $-0,04439$ & 0,14086 & $-0,84096$ & $-0,11875$ & $-0,07406$ & $-0,20995$ \\
\hline AEU & 0,71496 & 0,53753 & $-0,09552$ & $-0,16795$ & 0,01979 & 0,27421 & 0,55956 \\
\hline AUR & 0,92654 & 0,94555 & 0,06200 & 0,02088 & 0,14597 & 0,08146 & 0,01579 \\
\hline $\mathrm{AMcF}$ & 0,76094 & $-0,11818$ & $-0,13004$ & 0,42141 & 0,26861 & $-0,62342$ & $-0,30278$ \\
\hline AFSA & 0,89114 & 0,11290 & 0,93168 & 0,02446 & 0,07874 & 0,05954 & $-0,00363$ \\
\hline $\mathrm{ACS}$ & 0,86307 & 0,08880 & $-0,02734$ & 0,18996 & 0,06732 & 0,17431 & 0,88512 \\
\hline $\mathrm{ACF}$ & 0,89683 & 0,09383 & $-0,09620$ & 0,28241 & 0,05928 & 0,87918 & 0,15017 \\
\hline AFT & 0,82720 & $-0,19371$ & 0,10976 & 0,54298 & $-0,46744$ & 0,41688 & $-0,30086$ \\
\hline ATM & 0,90114 & $-0,01770$ & $-0,21967$ & $-0,10492$ & $-0,91711$ & 0,02177 & 0,00209 \\
\hline $\mathrm{AMtF}$ & 0,82435 & $-0,67536$ & 0,02356 & $-0,02363$ & 0,29512 & 0,04355 & $-0,52738$ \\
\hline AFSP & 0,89022 & $-0,09850$ & 0,90824 & $-0,16761$ & 0,12669 & $-0,08565$ & $-0,06434$ \\
\hline $\begin{array}{l}\text { Explicação } \\
\text { Explication }\end{array}$ & 0,25773 & 0,18397 & 0,13839 & 0,12479 & 0,07621 & 0,06337 & \\
\hline
\end{tabular}

AES - ângulo escápulo-solo; AEU - ângulo escápulo-umeral; AUR - ângulo úmero-radial; AMcF - ângulo Metacarpo-falangeano; AFSA - ângulo falange-solo anterior; ACS - ângulo coxal-solo; ACF - ângulo coxofemoral; AFT - ângulo fêmur-tibial; ATM - ângulo tíbiometatarsiano; AMtF - ângulo metatarso-falangeano; AFSP - ângulo falange-solo posterior.

AES - shoulder-floor angle; AEU - shoulder-humerus angle; $A U R$ - humerus-radio angle; AMcF-metacarpal-phalanx angle; AFSA - phalanx-floor-anterior angle; ACS - coxae-floor angle; ACF - coxae-femur angle; AFT tibia-femur angle; ATM - tibia-metatarsal angle; AMtF - metatarsal-phalanx angle; AFSP - phalanxfloor-posterior angle 
ANDRADE, L.S. Efeito da conformação sobre o tipo e eficiência da marcha. In: SIMPÓSIO NORDESTINO DO CAVALO MANGALARGA MARCHADOR - ANDAMENTO. 1, 1986, Recife. Anais... Recife: Pernambuco, 1986. p.31-34.

ASSOCIAÇÃO BRASILEIRA DOS CRIADORES DOCAVALO MANGALARGA MARCHADOR - ABCCMM. Belo Horizonte. Disponível em: 〈http://www.abccmm.org.br〉 Acesso em 26 março de 2003.

BARBOSA, C.G. Estudo morfométrico na raça Mangalarga Marchador. Uma abordagem multivariada. Belo Horizonte: Universidade Federal de Minas Gerais, 1993. 76p. Dissertação (Mestrado em Zootecnia) - Universidade Federal de Minas Gerais, 1993.

BRITO, A.A. Avaliação e Mensuração. Curso de capacitação de técnicos e árbitros da raça Mangalarga Marchador. Belo Horizonte: ABCCMM, 1990. 132p.

CABRAL, G.C. Avaliação morfométrica e estudo das curvas de crescimento de potros da raça Mangalarga Marchador. Dissertação (Mestrado em Zootecnia). Universidade Federal Rural do Rio de Janeiro, 2002.

CABRAL, G.C.; ALMEIDA, F.Q.; AZEVEDO, P.C.N. et al. Avaliação morfométrica de eqüinos da raça Mangalarga Marchador: Medidas Angulares. Revista Brasileira de Zootecnia, v.33, n.6, p.1790-1797, 2004a.

CABRAL, G.C.; ALMEIDA, F.Q.; QUIRINO, C.R. et al. Avaliação morfométrica de eqüinos da raça Mangalarga Marchador: índices de conformação e proporções corporais. Revista Brasileira de Zootecnia, v.33, n.6, p.1798-1805, 2004b.
CAMARGO, M.X.; CHIEFFI, A. Ezoognósia. São Paulo: CPA/ Intituto de Zootecnia, 1971. 320p.

KAHTTREE, R.; NAIK, D.N. Multivariate data reduction and discrimination with SAS ${ }^{\circledR}$ software. North Carolina: SAS Institute Inc., 2000. 559p.

LAGE, M.C.G.R. Caracterização morfométrica, dos aprumos e do padrão de deslocamento de eqüinos da raça Mangalarga Marchador e suas associações com a qualidade da marcha. Belo Horizonte: Universidade Federal de Minas Gerais, 2001. 114p. Tese (Doutorado em Ciência Animal) - Universidade Federal de Minas Gerais, 2001.

MORRISON, D.F. Multivariate statistical methods. 2.ed. New York: McGraw-Hill Company, 1976. 415p.

RIBEIRO JR., J.I. Análises estatísticas no SAEG. Viçosa, MG: Universidade Federal de Viçosa, 2001. 301p.

RIBEIRO, D.B. O cavalo: raças, qualidade e defeitos. Rio de Janeiro: Globo, 1988. 318p.

STATISTICA - STATISTICA for Windows 5.0. Tulsa: Statsoft Inc. 1995.

THOMPSON, K.N. Skeletal growth rates of weanling and yearling Thoroughbred horses. Journal of Animal Science, v.73, p.2513-2517, 1995.

Recebido em: 10/11/03

Aceito em: 29/09/04 